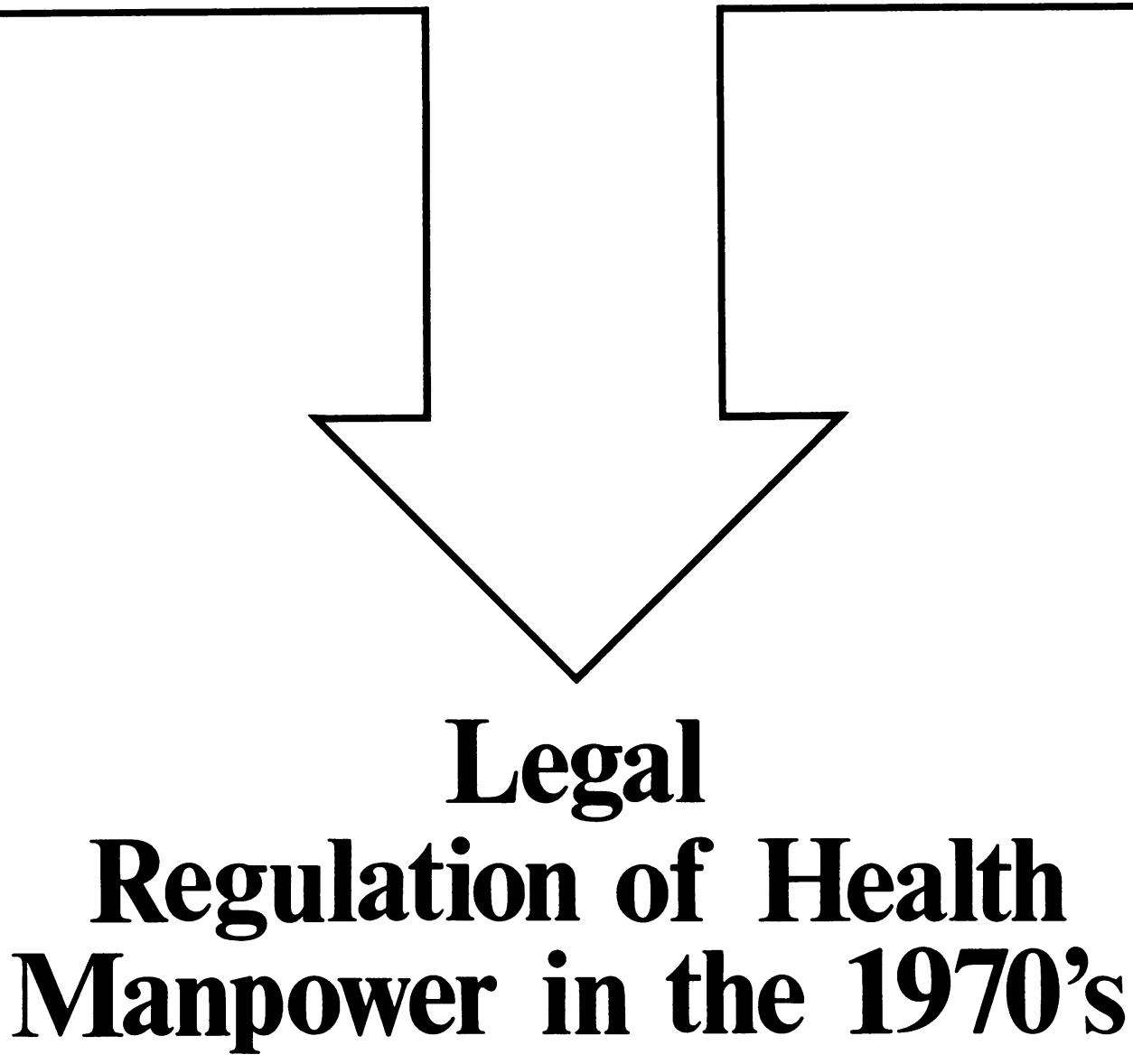

RUTH ROEMER, J.D.

Dr. Roemer is associate researcher in health law, Institute of Government and Public Affairs, University of California, Los Angeles. This paper was a resource paper for the 1971 Health Forum, San Francisco, March 15-17, 1971. It was prepared for the National Health Forum through arrangements made by the Study of Accreditation of Selected Health Educational Programs. Tearsheet requests to Dr. Ruth Roemer, Institute of Government and Public Affairs, University of California, Los Angeles, Calif. 90024.

THE FIRST medical licensure laws in the 1 United States were. enacted more than a hundred years ago (1) when the provision of health services was very different from the delivery of care today. Medical practice was conducted then by solo practitioners working largely alone in an entrepreneurial fashion. In 1900, physicians constituted 35 percent of all health workers (2). During this century State licensing laws regulating 25 other health professions and occupations have been passed. These laws generally have been patterned after the medical model.

Today the numbers of allied and auxiliary health personnel have so increased that physicians constitute only 9 percent of those employed in health services (2). New functions have emerged for existing kinds of personnel, and new kinds of personnel are being developed to meet the needs of modern health care. With health services increasingly provided in organized settings, such as hospitals, clinics, group practices, and now proposed health maintenance organizations, the laws designed a century ago to protect the public against incompetent and unethical solo practitioners have become obsolete. In fact, those 19th century laws have become a straitjacket on the delivery of health services in the quantity and quality the public needs and expects to receive. 
The effects of legal regulation of health manpower have received earlier attention than other aspects of the manpower problem, such as the need to rationalize the many different kinds of educational programs for allied and auxiliary health personnel $(3,4)$ or the system of accrediting educational programs, currently being studied jointly by the American Medical Association (AMA), the Association of Schools of Allied Health Professions, and the National Commission on Accrediting. Perhaps because the problems in licensure are particularly glaring or because our society has a low level of tolerance for legal prohibitions, actual or presumed, that impede good medical care, earlier attention was devoted to licensure rather than to other problems in manpower development. Research and documentation of the problems flowing from the licensing laws have been undertaken (5). Prestigious professional groups have addressed themselves to the issues and to formulation of policy (6-8). For the first time in nearly a century, significant amendments, discussed subsequently, have been made in the licensing laws.

As a result of this earlier work, the emphasis of this paper is not on problems but on solutions. Five preliminary steps, however, are necessary.

1. Define the needs in legal regulation of health manpower.

2. Specify the objectives of an effective regulatory system.

3. Outline the options or alternatives available to improve the licensing system.

4. Set forth the constraints affecting choice of these options.

5. Analyze the trade-offs among the aforementioned factors in the search for a sound solution or solutions to current problems.

\section{Underlying Assumptions}

Throughout this analysis, several underlying assumptions should be borne in mind.

First, many legal and voluntary controls besides licensure regulate the qualifications of health personnel and the ways in which manpower is used (9). The other legal controls include State hospital licensing laws requiring certain staffing arrangements, Federal regulations under Medicare and Federal certification of Medicare facilities, and other Federal aid programs requiring certain services and therefore personnel.

The voluntary measures include accreditation of educational programs for 15 occupations by the AMA Council on Medical Education; certification or registration by occupational groups of persons who meet certain requirements of education, experience, and competence; specialty board certification in medicine; standards set by other professions for specialty qualifications; requirements imposed by hospitals for admission to and remaining on their medical staffs and requirements for medical-related personnel, particularly many kinds of unlicensed technicians; criteria established by individual physicians for employment of auxiliary personnel in their private offices; and curricular requirements of educational programs. These controls, and the sanctions they entail, may be more important than the licensing laws in regulating health manpower, but in this paper consideration is given to the licensing laws and to other controls insofar as they influence the needs in licensure.

Second, problems in regulation of health manpower involve the total system of health care delivery. Although initially the issues involved in supply and quality of health manpower may seem to constitute a manageable, separate part of the overall problem of delivery of health services, in actuality the issues involve the larger questions of organization of health services. The recommendations that emerged from the task groups of the AMA's National Congress on Health Manpower in Chicago in October 1970 reflected the intertwining of manpower problems with the total delivery system.

Third, legal regulation cannot solve all the problems related to manpower. For example, one of the inhibitions on effective use of personnel is the fragmentation of the health service system into numerous agencies, each responsible for a segment of health services and each using the limited supply of trained health manpower in duplicative, disjointed, and uneconomic ways. Changes in the system of regulating health manpower cannot correct this deficiency, but at least the regulatory system should not aggravate it.

Fourth, solutions to current problems engendered by the licensing laws must take account of both present conditions and future eventualities. It would be folly to substitute for present strictures in the licensing laws different strictures that would, in time, create obstacles to effective delivery of services as great as current obstacles. Any changed system of regulating health manpower must therefore take account of certain facts of life: the team approach to the delivery 
of health services; the increasing organization of ambulatory services, just as inpatient services have been highly organized; and the likelihood of enactment of a national system of financing medical care through a combination of social insurance and general revenues.

If there is a single thesis for this paper, it is that the system of regulating health manpower must be related to the total system of health care delivery, current and projected.

\section{Needs}

The problems engendered by the licensing laws relate to two main aspects of health manpowersupply and quality. Supply of health manpower is affected by the standards specified in the licensing laws for entrance into an occupation, by provisions affecting geographic distribution of personnel, and by definitions of scope of functions determining how personnel may be used. Quality of health manpower is affected by standards for initial entrance into the occupation, to some extent by regulation of mobility, by definitions of scope of functions, and also by control of quality of personnel on a continuing basis.

\section{Standards for Initial Entrance}

The various licensing laws set forth stringent and specific educational requirements that allow little flexibility in qualifications or experience (5). In some instances, even the content of required courses and the length of required training are set forth. These requirements may be so specific as to restrain educational innovation $(5 a, b)$. The requirement of graduation from an "approved" or "accredited" program may be so vague or so variable in its interpretation as to provide little protection of the quality of educational preparation. In recent years, with the demand of unions and communities for greater job opportunities, it has become clear that the specific educational requirements in the licensing laws block entrance into the health occupations of persons with considerable, if unorthodox, background in the health services, such as medical corpsmen, and impede upward mobility of persons already in the health industry.

In response to this restriction in the licensing laws on the supply of manpower, proficiency examinations are being developed in various disciplines to measure a person's competency to perform certain jobs, and equivalency examinations are being developed to equate nonformal learning with that achieved in academic courses or training programs $(10,11)$.

In 1969 California enacted legislation to authorize recognition of equivalency qualifications in three ways (12).

REQUIRING RECOGNITION OF THE TRAINING OF MEDICAL CORPSMEN WHO SEEK TO BECOME REGISTERED NURSES. A former medical service technician in the armed services may be licensed as a registered nurse on approval of his training by the California Board of Nursing Education and Nurse Registration and on passing the standard licensing examination $(12 a)$.

REQUIRING RECOGNITION OF EQUIVALENT EDUCATION OR EXPERIENCE OF CANDIDATES FOR LICENSURE AS VOCATIONAL NURSES. Licensure of vocational nurses is authorized, provided the candidate passes the licensing examination. Moreover, the accreditation of a school of vocational nursing that denies credit for acquired knowledge by use of challenge examinations or other methods of evaluation may be revoked $(12 b)$.

FACILITATING UPWARD MOBILITY FROM VOCATIONAL NURSE TO REGISTERED NURSE BY ALLOWING CREDIT FOR VOCATIONAL NURSING TRAINING. The additional preparation required for a vocational nurse to be eligible for examination as a registered nurse is not to exceed 30 units in nursing and related subjects $(12 c)$.

Thus, one need is that the licensing laws provide sufficient flexibility in governing initial minimum standards of qualification to recognize alternative education and experience as equivalents of formal academic training. Another related need is that these standards allow for, and positively encourage, lateral and vertical mobility to enable personnel obtaining additional training to progress to jobs requiring the same or higher levels of skill.

\section{Geographic Distribution}

Licensing laws are enacted under the State's police power to protect the health and welfare of its citizens. As such, they erect barriers to the mobility of health personnel across State linesa stratagem that may have more to do with a profession's desire to control competition than to protect the public from persons qualified in accordance with different standards. All States, except Florida and Hawaii, provide some means of recognizing physicians' licenses of other States, but only eight States-Connecticut, Indiana, Massachusetts, Montana, Nebraska, Ohio, South Carolina, and Virginia-reciprocate or endorse the 
licenses of all other jurisdictions $(5 c)$. Restrictions on interstate recognition of licenses exist in other disciplines too.

Among the forces contributing to easing restrictions on interstate mobility are the trend toward discretionary, rather than mandatory, reciprocity requirements and the development of nationally uniform examinations. For more than 30 years, the State Board Test Pool Examination in nursing has provided a national basis for recognizing out-of-State nursing licenses $(5 d)$. The examination of the National Board of Medical Examiners and, more recently, the Federal licensing examination-FLEX, developed by the Federation of State Medical Boards - may similarly lead to easing restrictions on interstate movement of physicians. Just as design of adequate equivalency examinations can break the deadlock on recognition of alternative qualifications, so accepted national examinations may provide the basis for eliminating barriers to recognition of licenses of other States.

Encouraging equitable distribution of health personnel to areas where they are needed is complex, but licensing laws should not bar interstate movement of personnel with substantially equivalent qualifications. The need is to eliminate arbitrary or unreasonable barriers to interstate movement of personnel.

\section{Use of Personnel}

The central issue in licensure concerns the scope of functions of the many and increasing kinds of health personnel. One solution to the critical shortage of physicians and other professionals is vastly expanded use of allied and auxiliary health workers. A 4 percent increase in physician productivity, Fein estimated, can add the equivalent of 1 year's medical school graduating classes to the medical market (13). This increase in productivity can be achieved only by relieving the physician of tasks not requiring medical judgment and by delegating them to qualified members of the health team. Thus, the role of nurses has been expanded to include provision of ambulatory medical care and health surveillance for mothers, children, and the chronically ill $(14,15)$. Physician's assistants are now trained in numerous programs, and many kinds of technicians and aides have been trained for specific functions in hospitals and other institutions.

These developments conflict with licensing laws which define the permissible scope of functions for each licensed category of personnel. As Prof. Nathan Hershey, University of Pittsburgh Law Center, has described, the physician is authorized to perform all functions in medical care, but other personnel may perform only a segment of these functions (16). Being phrased in general terms, statutory definitions of the scope of functions for different kinds of personnel leave vague the exact limits of authority for each category. On the one hand, this vagueness has permitted innovations in use of personnel. On the other hand, fear of either incurring liability in a lawsuit charging negligence or of losing malpractice insurance deters delegation of functions not authorized by "custom and practice."

Actually, few court decisions have imposed liability for exceeding functions defined in the licensing laws $(5 e, f)$, but the fear remains and inhibits delegation. Not only the vagueness of definitions but specific prohibitions may restrict scope of functions. Thus, the laws pertaining to pharmacy may restrict the functioning of nurses with respect to issuance of medications to the prejudice of sound delivery of medical care $(12 d)$. For example, nurses may not be authorized to issue routine refills of medication in a program of preventive isoniazid treatment when the patient's supply is exhausted in view of interpretation of a pharmacy law as prohibiting nurses from prepackaging or repackaging dangerous drugs.

The physician's assistant is a response to restrictions in the licensing laws on use of personnel. Two contrasting statutes have been enacted. The Colorado Child Health Associate Law permits the medical licensing board to certify specially trained child health associates to provide medical care to children under the supervision of a physician, mainly in the physician's office (17). The authorized functions of the child health associate are spelled out in the statute, and the pediatrician, who must be approved by the licensing board for this purpose, is permitted to supervise only one associate.

Unlike the Colorado statute, which is a licensing law, the California physician's assistant law, also an amendment to the medical practice act, is a registration act $(12 e, 18)$. The California law permits approved physicians to hire assistants from approved training programs, one physician to supervise no more than two assistants. Except for certain prohibited functions, the services which the physician's assistant may perform are not spelled out in the statute. The exact form that 
implementation will take will depend on regulations of the board of medical examiners, aided by a statutory advisory committee.

While the licensing laws inhibit flexible and innovative uses of personnel, which are justified by advances in technology and improvements in education, they leave unregulated the functions of the proliferating kinds of technicians and aides -medication technicians, surgical technicians, neurologic technicians, or the various kinds of aides. These nonprofessionals are subject to no controls except the regulations of the individual institutions in which they work and the remote surveillance of the Joint Commission on Accreditation of Hospitals. Thus, the needs are to remove barriers to delegation of functions to properly qualified personnel and to write into the regulatory system provisions for flexible and innovative use of all members of the health team with proper supervision and appropriate organizational controls.

\section{Continuing Quality of Personnel}

Nearly all licensing laws grant lifetime licensure unless the licensee is guilty of criminal conduct or gross incompetence $(5 g, h, i)$. No updating of qualifications is required for renewal of a license (except for osteopaths) despite the recommendation of the National Advisory Commission on Health Manpower in 1967 that “. . . Relicensure should be granted either upon certification of acceptable performance in continuing education programs or upon the basis of challenge examinations in the practitioner's specialty" (19).

No State has enacted any requirement for challenge examinations or continuing education as a condition of license renewal since this recommendation was made, but medical specialty groups and medical societies are requiring or encouraging continuing education. The difficulty with this voluntary approach is that those whose qualifications may most need updating may not obtain it.

A serious question concerning quality of personnel relates to licensure of chiropractors and other unscientific personnel. The rationale for mandatory licensure of chiropractors was to limit their scope of functions $(5 j)$. In actuality, licensure does not protect the public because chiropractic is inherently unscientific (20). Chiropractic treatment not only produces actual physical damage to some patients but often delays proper medical care until their illness is irreversible. Licen- sure provides an unwarranted assurance to the public of the legitimacy of chiropractic.

Since the licensing boards are composed mainly of members of the profession for which the candidates are seeking to be licensed, the system is, in effect, a system of self-licensure. Technical and scientific qualifications should be evaluated by members of the profession, but issues pertaining to public policy in licensure should be decided by a body representative of all providers of health care, health facilities, and governmental agencies responsible for health services.

One need is for some method of requiring updating of qualifications of health personnel. Another need is to make the licensing agencies more responsive to the public interest than they are.

\section{Objectives}

Traditionally, licensing laws have been designed to specify minimum levels of competence for the occupation necessary to protect the public (21), but the aforementioned problems may call for a change in thinking. Vast improvements in educational programs and the drive for national standards in education, assisted by a strengthened system of accrediting, suggest that perhaps the time has come to conceive of licensure as having a broader purpose than regulation of minimum qualifications. The following list summarizes the objectives of a sound legal system regulating health manpower in contemporary American society.

1. Eliminate legal barriers to an increased supply of health manpower.

2. Permit lateral and vertical mobility of personnel.

3. Allow maximum productivity of health professionals and optimal use of all members of the health team.

4. Encourage innovations in use of personnel, with protection of practitioners against legal sanctions as a result of such innovations.

5. Facilitate interstate mobility and more equitable geographic distribution of personnel.

6. Require effective controls of the quality of personnel, both with respect to initial entrance into the occupation and continuation in it.

7. Integrate regulation of health personnel with regulation of health facilities and the overall health care system.

8. Provide for public accountability.

9. Protect the public, not the persons licensed.

10. Evolve a system of regulation sufficiently flexible to take account, without undue lag, of 
new needs, new knowledge, and changed technological and social conditions in health services.

The licensing laws cannot be expected to accomplish all 10 of the listed objectives. The laws, however, should not create impediments to increased supply, more extensive use, and improved quality of health manpower.

\section{Options}

Numerous solutions to the problems created by the licensing laws have been proposed. Most proposals require action by State governments; a few urge action at the Federal level, and some necessitate efforts of voluntary professional and occupational groups. These options are not mutually exclusive although some represent alternative approaches. To facilitate their consideration, the options are numbered and discussed in relation to the four main problems associated with licensing laws (see the preceding section on Needs). Some of the recommendations apply to more than one problem.

\section{Standards for Initial Entrance}

1. Amend existing licensing laws to require recognition of equivalency qualifications and to encourage use of proficiency examinations with respect to knowledge and skills.

2. Amend existing licensing laws to provide for a ladder of occupations in various fields and clusters of related occupations through which health workers can move with appropriate or additional education or experience.

\section{Geographic Distribution}

3. Use nationally recognized licensing examinations for each licensed occupation instead of differing State examinations.

4. Establish a national, uniform system of accrediting educational programs in all health occupations.

5. Develop national model licensing codes for the health occupations for adoption by the States.

6. Provide, in connection with a program of national health insurance, that a physician, dentist, optometrist, podiatrist, nurse, pharmacist, or other professional for whom licensure is required in all States, who is licensed in one State and meets national standards, be eligible to furnish services in any other State under the program. The permissible scope of the licensee's practice would be governed by the State in which he is practicing. Other professional and nonprofessional personnel who are licensed in any State would be authorized to function in all States if they meet national standards. Use of ancillary personnel would be authorized in organized settings in accordance with national standards. This option applies to use of personnel as well as to interstate mobility.

These options are limited to legal measures. They do not include economic incentives (forgiveness of loans for medical education, financial support for construction of physicians' offices, and tax benefits) for location in rural areas, urban ghettos, and other areas of need. For example, Minnesota Statutes, sections 147.24-.28 (1969) provide for loans up to $\$ 2,500$ per year at 8 percent interest to be granted to needy medical students, with 1 year's interest to be forgiven for each year that the recipient practices in a Minnesota municipality of less than 3,000 persons and 25 percent of the principal to be forgiven for 5 years' practice in such a community. (Options 3 and 4 also pertain to the quality of personnel.)

\section{Use of Personnel}

7. Continue to license additional health occupations. Such licensing would remove the fear of liability and authorize additional categories of personnel, but it would accentuate fragmentation of functions by creating additional segments of function; for example, physical therapy assistants are now licensed in seven States.

8. Expand voluntary accreditation of educational programs, as is now done by the AMA Council on Medical Education, and voluntary certification or registration of personnel by occupational groups. Certification and registration provide for national standards, but they are, in effect, self-regulation by the occupation to be regulated with weak mechanisms for enforcement of standards.

9. Amend the medical practice acts to authorize broadened delegation of function as has been done in Arizona, Colorado, Kansas, and Oklahoma. The Oklahoma statute authorizes service by "a physician's trained assistant, a registered nurse, or a licensed practical nurse if such service be rendered under the direct supervision and control of a licensed physician" $(5 k, 18,22)$. Such a provision may provide increased protection against liability, but it gives statutory sanction to only those functions already adopted in custom and practice. Truly innovative use of personnel would still be inhibited. 
10. Amend existing licensing laws to expand the scope of functions of ancillary personnel, in accordance with current or expanded training. For example, the restriction of dental hygienists to prophylaxes, taking roentgenograms, and topical application of fluoride is a waste of health manpower. Iowa, Minnesota, Alabama, Missouri, North Carolina, Pennsylvania, and South Dakota have authorized limited expansion of functions, and a strong case can be made for using dental hygienists to their full present or potential capacity (23).

11. Reexamine existing licensing laws and regulations in light of current training and actual functions of health personnel, so as to eliminate legal restrictions on the functions of licensed personnel and on reasonable use of unlicensed auxiliaries. Thus, the pharmacy laws should be amended to permit reasonable functioning of registered nurses with respect to issuance of medications. All licensing laws should permit assignment of ministerial and technical tasks to properly qualified and supervised auxiliaries.

12. Amend existing licensing laws to permit certification of new kinds of personnel, such as physician's assistants, and to authorize the functioning of existing personnel not now fully utilized, for example, nurse-midwives. Professional nurse-midwives are licensed now only in New Mexico, the eastern counties of Kentucky, New York City, and recently in Utah, but these highly qualified professionals could boost the resources for maternity care in urban and rural areas $(5 l)$.

13. License or approve the employer or user of new kinds of personnel. Both the Colorado Child Health Associate Law and the California physician's assistant law contain this provision.

14. Establish a statewide committee or board or authorize the board of medical examiners to regulate innovations in using allied and auxiliary personnel. To some extent, this approach is incorporated in the California physician's assistant law by the board's authority to issue regulations, but this option would provide broader authority.

15. Retain individual licensure for professionals to whom the public has direct access, but for persons working in organized frameworks, develop a system of licensure of health teams. The head of the team would be licensed as an individual and authorized to supervise certain kinds of unlicensed personnel working in his team, provided specified criteria of good patient care were met (24). This system of licensure would apply to health teams working in hospitals, extended care facilities, clinics, neighborhood health centers, group practices laboratories, and other multidisciplinary organizations.

16. Expand hospital licensure to include jurisdiction over use of health manpower. This plan of so-called institutional licensure proposed by Hershey (25) would distinguish between health personnel to whom the public has direct access (who would continue to be licensed as individuals) and personnel functioning within an institutional framework where team provision of services and surveillance by the institution would protect the public. An important element in this proposal is regulation by a State agency, accountable to the public, of job classifications, required training, and appropriate supervision.

Still another option to acquire more health manpower and extend its use is to develop national standards for duties of personnel through a national model code (option 5) or through provisions in a system of national health insurance (option 6).

\section{Continuing Quality of Personnel}

17. In order to prevent educational obsolescence, require challenge examinations in the practitioner's specialty or approved continuing education courses as a condition of relicensure. Professional associations and specialty boards are encouraging increased continuing education on a voluntary basis.

18. Discourage practice by unscientific personnel through exclusion of such practitioners from Federal and State reimbursement (particularly Medicaid) and revoke Federal recognition of chiropractic by the Office of Management and Budget, U.S. Immigration Service, Selective Service, Internal Revenue Service, and State workmen's compensation and other laws.

19. Prepare for phasing out chiropractic by (a) prohibiting enrollment in schools of chiropractic by a date 5 years hence and $(b)$ providing for additional training of chiropractors who wish to become fully qualified physical therapists or enter some other health profession, such as rehabilitation counseling.

20. Restructure licensing boards to make the regulatory bodies for health manpower representative of all providers of health service and the public, as well as the occupation licensed, and to integrate regulation of health manpower with regulation of health facilities. 


\section{Constraints}

Choices among the aforementioned options or a combination of the options will depend on weighing the constraints that may exist on the alternatives. The following basic question must be asked: Is the option so promising and so viable as to warrant the steps necessary to overcome the contraints that may exist? These constraints may be divided into five groups.

Administrative constraints. Does the option require establishment of criteria that may be difficult to define for general application? Does it require unreasonable numbers of qualified personnel for administration and surveillance? Does it involve excessively difficult or unworkable administrative procedures? Does it make more complex the current multiplicity of jurisdictions governing health services? Administrative constraints deal with more than efficiency. They are determinatives of a workable, enforceable system of regulating personnel.

Financial constraints. Does the option impose excessive financial costs for administration and surveillance? For retraining of personnel? For malpractice insurance coverage? Will it be expensive to initiate but have low operating costs? The critical spiralling of costs of health care necessitates a logical system that will use financial resources wisely.

Time constraints. Is the option sufficiently developed and tested to be implemented with adequate speed? Is a demonstration or trial period warranted? Can the option be viewed as a shortterm measure to be followed by more fundamental solutions requiring more time? Time is important because of urgent manpower shortages within the health services.

Legal or constitutional constraints. Is the option within the purview of the State or Federal government? How does it affect the possibility of lawsuits and disciplinary actions against health personnel? Does it substitute rigid new laws for current inflexible controls? Does it mandate accountability to the public? In any revision of the law the determining factor should be the health needs of people.

Political and institutional constraints. Is the option politically realistic and feasible in light of vested interests of professional and occupational groups? Is it based on awareness of practices of institutions and facilities? Is it contrary to professional attitudes that inhibit changed use of personnel? Does it require adequate medical supervision and protection of the public? Does it recognize pressures from the community and unions for employment and upward mobility of auxiliary workers? Does it comply with the current demand for consumer participation in the delivery of health care? Does it respond to longstanding unmet health needs and rising public demand for medical care? Does it consolidate formerly fragmented functions or promote a more rational and coordinated system of health care accessible to all? Any change encounters political and institutional opposition, but this opposition may be overcome by strong and meritorious countervailing forces.

\section{Trade-Offs}

Each of the aforementioned alternatives is now examined as it relates to the needs, objectives, and constraints. To the extent to which each option meets the requirements and is subject to constraints, a judgment, admittedly subjective, is made as to the advisability of selecting it.

Options 1 (recognition of equivalency qualifications) and 2 (opportunity for lateral and vertical mobility) meet both the needs and objectives. They would foster increased recruitment and retention of health manpower. Option 1 may be impeded by political resistance of professional groups, but this is not insuperable, as the California legislation shows. Option 2 may be deterred by requirements for surveillance of training for related or higher level jobs, but the advantages of this alternative are so great that this difficulty should be overcome. Both these options should receive a high priority.

Options 3 (national licensing examinations) and 4 (national system of accrediting) are important elements in any system to eliminate barriers to geographic mobility. These options would also contribute to improved quality of personnel. They are not only realistic options, but they are imminent. Options 3 and 4 should receive a high priority for all occupations, and the timetable for their implementation should be accelerated.

These options, however, do not have the capacity to eliminate all legal barriers to interstate mobility currently created by the licensing laws. Therefore, consideration should be given also to options 5 (national model code) and 6 (personnel regulation under a national health insurance program). Of these two alternatives, option 5 faces political and temporal constraints in that each State would have to enact a model code. 
Option 6, while not an immediate possibility, would not face the same political constraints once the basic legislation is adopted. It probably does not face legal constraints because the authority of Congress to override State laws in a program of Federal expenditures derives from the power to provide for the general welfare and flows from the Supremacy Clause of the Constitution (26, 27). Time is the greatest constraint on option 6 because it may be several years until a national health insurance law is enacted. Option 6 should receive a high priority as a means of establishing a sound, effective, national standard for regulation of personnel.

With respect to use of personnel, option 7 (continue to license additional categories) is at variance with the need for optimal and innovative use of health personnel and would accentuate the current fragmentation of functions. Licensure of additional categories of personnel will further harden current rigidities of the present system. This option is negated by political constraints engendered by the urgent needs of health facilities for flexible use of personnel and by the public pressures for adequate medical care. For this reason, the Department of Health, Education, and Welfare has recommended a 2-year moratorium on licensing new categories of health manpower with statutorily defined scopes of functions until a more satisfactory solution is developed (28). Option 7 should be rejected.

Option 8 (expansion of the current system of voluntary accreditation of educational programs and certification of personnel) is oriented toward needed national standards, but it omits public accountability and perpetuates fragmentation of functions. As now conducted, voluntary certification or registration is self-regulation by the occupation itself. The current study of accreditation of selected health educational programs will undoubtedly provide recommendations to strengthen the system of accrediting and thus lead to improvements in educational programs. Further work should also be done to define the appropriate participation of occupational groups in setting standards and designing examinations for their occupations.

Option 9 (authorization for broadened delegation of functions) is designed to meet the need for expanded use of auxiliaries, but it fails to insure adequate public protection because no guidelines are stipulated for the delegation. Moreover, it does not provide protection against liability for delegation of duties beyond custom and practice. In Colorado, where such a broadened delegation statute is in force, it was deemed necessary nevertheless to enact a separate Child Health Associate Law to authorize the functioning of this new kind of health worker. Therefore, option 9 is not an adequate solution. It might be adopted, however, as an interim measure to demonstrate legislative intent in favor of broadened delegation pending adoption of other solutions but without any illusions as to its protection of innovative use of health manpower.

Option 10 (amend current licensing laws to expand scope of functions for existing personnel) gives immediate relief from restricted definitions of scope of functions for the particular kind of personnel involved. It does not, however, provide a system of regulation with sufficient flexibility or capability to meet future problems. Although option 10 will encounter opposition deriving from ingrained professional attitudes, it should be adopted for dental hygienists and other allied and auxiliary personnel who are working at levels below those warranted by their education and training.

Option 11 (reexamination of impingement of licensing laws for one profession on functions of another) is addressed to the need for flexible functioning of personnel and to the objective of adapting the regulatory system to technological and organizational developments. Although option 11 cannnot solve basic problems in the licensing system, it can nullify specific obsolete provisions in the laws or regulations. It should be adopted.

Option 12 (certification of physician's assistants and authorization for other personnel) proposes increasing health manpower and assigning segments of medical care to specialized personnel. It meets the objective of maximum productivity of health professionals and optimal use of all members of the health team.

Physician's assistants and nurse-midwives, for example, can assume a large share of medical care. In order to counteract the political constraint of inadequate medical supervision, these health workers should work primarily in organized settings with appropriate institutional controls. The financial constraint of the cost of training programs is offset by the large contribution such health personnel would make to the provision of services. If authorization for the functioning of such personnel is accomplished by amendment of existing laws, with definition of functions left 
to regulations (as done in the California physician's assistant legislation), the legal constraint of promoting new rigidities in the regulatory system is overcome. Option 12 should be adopted with appropriate controls.

Option 13 (user licensure) authorizes employment of an extra pair of hands but inadequately protects the public unless other controls are imposed. The danger is that variable standards would exist for using personnel. The main constraint is administrative in that it is difficult to establish criteria for licensing users and to find ways to provide surveillance. Option 13 seems viable only if adopted in conjunction with other measures. Experience under the Colorado Child Health Associate Law and the California physician's assistant law should provide helpful insights.

Option 14 (statewide committee or board to regulate innovations in use of health manpower) meets the need for authorizing innovations in use of personnel, but it encounters administrative constraints related to drafting guidelines for innovative use and to incorporation of measures with demonstrated efficacy into the system. Further consideration should be given to option 14 .

Option 15 (licensure of health teams) advantageously relates the regulatory system to modern provision of health care. From the point of view of protection of the public, it distinguishes between health practitioners to whom the public has direct access and personnel working in an organized setting. But it runs into administrative constraints related to the design of health teams and perhaps legal constraints related to liability of the head of the team for acts performed by other members of the team. Option 15 should be given consideration for selected groups of health workers, such as laboratory personnel.

Option 16 (institutional licensure) meets the objective of a regulatory system sufficiently flexible to take account of new functions, knowledge, and organization. Job classifications would be submitted by the institution to a State agency, with qualifications specified for entry and step promotions. Governmental surveillance would achieve the objective of integrating regulation of facilities and personnel. The main constraint is political or institutional because the proposal represents a marked departure from the present order. Appropriate medical supervision would need to be built into a system of institutional licensure and provision made for movement of personnel among institutions. Despite these constraints, on balance option 16 is promising and, fortunately, trials of this option are in process.

With respect to quality of personnel, option 17 (relicensure or required continuing education) meets the objective of updating qualifications. Challenge examinations in the practitioner's specialty are unpopular and are of dubious value. Required continuing education as a condition of relicensure, although subject to administrative, political, and financial constraints, is preferable to a variable voluntary system. Option 17 should receive a high priority.

Options 18 and 19 (elimination of cloak of legitimacy for cultists) are designed to protect the public against unscientific practitioners and to eliminate wasteful use of health manpower. These options would encounter political constraints, but some scientists and lawyers would favor redirecting chiropractors into other health occupations. If a national health insurance law is enacted, chiropractors probably will be excluded from reimbursement, as they now are excluded from participation in Medicare. Work should begin towards options 18 and 19.

Option 20 (make licensing boards representative of providers and the public) is designed to increase public accountability in the licensing process and to integrate regulation of health personnel with the health care delivery system. It may encounter political constraints from professions long accustomed to self-licensure, but the benefits of participation by providers and the public are so great that these benefits should outweigh any vested interests. Option 20 should be adopted.

\section{Conclusions}

These various proposals can be divided into two kinds. One kind retains individual licensing laws with their fragmented scopes of functions but corrects the most egregious features of the system. This kind may alleviate the problems but cannot solve them.

The other kind of proposal, for example, institutional licensure and national standards under a system of national health insurance, envisions a bold approach to develop a system of regulation geared to the modern reality that medical care is increasingly provided by teams of personnel working in organized frameworks.

In making a decision as to which proposals should be adopted, it may be helpful to select 
some short-range solutions that can be accomplished with relative ease and then to develop further, more fundamental, long-range solutions. In this agonizing reappraisal, health professionals and consumers will need to interact constructively.

\section{REFERENCES}

(1) Shryock R.: Medical licensing in America, 1650 1965. Johns Hopkins Press, Baltimore, Md., 1967.

(2) Pennell, M. Y., and Hoover, D. B.: Health manpower source book 21 . Allied health manpower supply and requirements, 1950-80. Table 1, p. 3. PHS Publication No. 263, sec. 21. U.S. Government Printing Office, Washington. D.C., 1970.

(3) Carpenter, E. S., Wallace, G. J., and Killian, J. D.: Education for health care in Michigan. Report of the Citizens Committee on Education for Health Care. Education for Health Care Publications, Ser. 1, No. 5. Michigan Department of Education, Lansing, 1970.

(4) Reeder, L. G., Roemer, R., and Sprowls, H. C.: Education of health manpower in California. A survey of programs for preparing selected categories of personnel. Report for the California Committee on Regional Medical Programs. Survey Research Center, University of California, Los Angeles, 1968. Processed.

(5) Forgotson, E. H., Roemer, R., and Newman, R. W.: Legal regulation of health personnel in the United States. In Report of the National Advisory Commission on Health Manpower. U.S. Government Printing Office, Washington, D.C., 1967, vol. 2, pp. 279-283; (a) p. 302; (b) pp. 304-305; (c) p. 310 ; (d) p. 416 ; (e) pp. 292294; $(f)$ pp. 423-428; $(g)$ pp. 309-310; $(h)$ p. 322; (i) pp. 501-502; $(j)$ pp. 326-330; $(k)$ pp. 294-295; (l) pp. 416-417.

(6) Educational preparation for nurse practitioners and assistants to nurses: A position paper. American Nurses Association, New York, 1965.

(7) Statement on licensure of health care personnel. Pamphlet No. S-67. American Hospital Association, Chicago, Ill., 1971.

(8) National Congress on Health Manpower: Summation of task group reports. Council on Health Manpower, American Medical Association, Chicago, Ill., 1971. In press.

(9) Roemer, R.: Legal and other institutional impediments to realignment of health service functions. In Expanding the supply of health services in the 1970's: Report of the National Congress on Health Manpower, October 22-24, 1970. Council on Health Manpower, American Medical Association, Chicago, Ill., 1971, pp. 43-64.

(10) National Committee for Careers in Medical Technology: Interdisciplinary groups plan proficiency examinations. GIST No. 48, pp. 1-3, November 1970.
(11) National Committee for Careers in Medical Technology: Equivalency and proficiency testing related to the medical laboratory field. A summary. Bethesda, Md., March 1970. Processed.

(12) West's Ann. Calif. Code, bus. \& prof. code, sec. 710; (a) sec. 2736.5; (b) sec. 2873; (c) sec. 2881.1; (d) sec. 4051; (e) sec. 2510.

(13) Fein, R.: The doctor shortage: An economic diagnosis. The Brookings Institution, Washington. D.C., 1967, p. 138.

(14) Lewis, C. E., Resnik, B. A., Schmidt, G., and Waxman, D.: Activities, events and outcomes in ambulatory patient care. N Engl J Med 280: 645649, March 1969.

(15) Lewis, C. E., and Resnik, B. A.: Nurse clinics and progressive ambulatory patient care. N Engl $\mathbf{J}$ Med 277: 1236-1241, December 1967.

(16) Hershey, N.: Licensing for the health professions. In Proceedings of American Nurses' Association conference for members and professional employees of State boards of nursing and American Nurses' Association Advisory Council, Dallas, Tex., May 9-10, 1968. American Nurses Association, New York, 1969, pp. 8-9.

(17) Colo. Rev. Stat., sec. 91-10-1 (supp. 1969).

(18) Curran, W. J.: Health services manpower roadblocks: Legislative measures to facilitate development of allied manpower roles. Paper presented to the annual meeting of the American Public Health Association, Houston, Tex., Oct. 26, 1970.

(19) Report of the National Advisory Commission on Health Manpower. Vol. I. U.S. Government Printing Office, Washington, D.C., 1967, p. 42.

(20) Independent practitioners under Medicare. A Report to the Congress. Department of Health, Education, and Welfare, Washington, D.C., December 1968, pp. 146-197.

(21) Occupational licensing legislation in the States. Council of State Governments, Chicago, Ill., 1952, p. 53.

(22) Okla. Stat., tit. 59. sec. 492 (supp. 1966).

(23) Roemer, R.: The legal scope of dental hygienists in the United States and other countries. Public Health Rep 85: 941-948, November 1970.

(24) Roemer, R.: Licensing and regulation of medical and medical-related practitioners in health service teams. Med Care 9: 42-54, January-February 1971.

(25) Hershey, N.: An alternative to mandatory licensure of health professionals. Hosp Progr 50: 71-74, March 1969.

(26) U.S. Congress: A bill to create a health security act. S. 4297, sec. 56. 91 st Cong., 2d Sess., 1970.

(27) Kennedy, E. M.: Introduction of the health security act. Section-by-section analysis. 91st Cong., 2d Sess. Congr Rec A14338-S14363, Aug. 27, 1970.

(28) Office of the Assistant Secretary for Health and Scientific Affairs: Report on licensure and related health personnel credentialing. OM 2481. U.S. Department of Health, Education, and Welfare, Washington, D.C., June 1971. 